\title{
MULTIPLICIDADES DA IMAGEM: A ARTE E OS AFETOS
}

\author{
Aurélia Regina de Souza Honorato*
}

\begin{abstract}
Resumo: Este texto é um recorte de meu estudo para doutoramento que teve como problema de pesquisa a seguinte questão: é possível, por meio do sensível, promover uma formação de professores e professoras de Artes com potencial crítico e político? Uma formação para um novo professor e professora que a partir da experiência cria modos de vida e assim cria uma nova aula de Artes? Nele trago reflexões acerca da imagem, especialmente a imagem na arte como exercício do olhar, buscando avançar os limites da cronologia para alcançar a imagem em sua multiplicidade. A partir de autores como Georges Didi-Huberman, Jacques Rancière, Emanuelle Coccia, Gilles Deleuze e Félix Guattari, o texto tem também como objetivo pensar a mobilização que a arte promove como afeto que, de modo reflexivo, promove um novo olhar, um novo ouvir, um novo sentir sobre as coisas do mundo.
\end{abstract}

Palavras-chave: Imagem. Afeto. Arte.

A imagem é ao mesmo tempo um objeto, uma figura e um lugar de experiência. Ela pode te atravessar sem deixar marcas, mas ela pode te penetrar e te modificar. Pode promover em ti uma mudança no modo de olhar para a vida, pode te afetar. E é olhando para esse panorama que busco entender os conceitos de imagem a partir de pensadores contemporâneos da filosofia, da arte, da cultura e da história da arte.

Escolho, aqui, para iniciar uma reflexão sobre a imagem, um diálogo com Nicola Abbagnano (2007) a partir de seu Dicionário de Filosofia, onde o conceito de Imagem ${ }^{1}$ é semelhança ou sinal das coisas que pode conservar-se independentemente das coisas. $\mathrm{Na}$ filosofia antiga, consideravam-se as imagens como as coisas sensíveis, só que sem matéria, produto da imaginação. Assim como também, num segundo significado, imagem é sensação ou percepção, vista por quem a recebe. Para os estoicos, imagem é a marca que a coisa deixa na alma, marca que é uma mudança da própria alma. A imagem propriamente dita é "aquilo que é impresso, formado e distinto do objeto existente, que se conforma à sua existência e por isso é o que não seria se o objeto não existisse" (DIÓG. L, VII, 50 apud ABBAGNANO, 2007, p. 537).

Esses conceitos passaram para a Idade Média e foram utilizados com fins teológicos para esclarecer a relação entre a natureza divina e a humana. Na filosofia moderna, estes conceitos foram retomados por Francis Bacon (1561 - 1626) e Thomas Hobbes (1588 1679). Para este último, a imagem "é ato de sentir e só difere da sensação assim como o fazer difere do fato" (De corp., 25, § 3 apud ABBAGNANO 2007, p. 537). Na filosofia geral, o termo imagem começou a perder espaço para o termo ideia, a partir de René Descartes $^{2}$ e também para o termo representação a partir de Christian Wolff ${ }^{3}$. Na filosofia

\footnotetext{
* Doutora em Ciências da Linguagem pela Universidade do Sul de Santa Catarina. Professora na Universidade do Extremo Sul Catarinense. E-mail: ars.honorato@gmail.com.

${ }^{1}$ Do latim Imago; inglês Image; francês Image; italiano Immagine.

${ }^{2}$ René Descartes (1596 - 1650): filósofo, matemático e físico francês do século XVII. Fez estudos na área da Epistemologia e Metafísica. É considerado o pioneiro no pensamento filosófico moderno.

${ }^{3}$ Christian Wolff $(1679$ - 1754): filósofo alemão que popularizou o Deísmo, posição filosófica que aceita a existência e a natureza de Deus através da razão e do livre pensamento.
} 
moderna, Henri Bergson é um marco quando substitui pela visão biológica a visão materializante da ciência e da metafísica representando o fim da era cartesiana. Seu pensamento inova, fundamentalmente, no tipo de ruptura que introduz no racionalismo do século XVII a partir de sua visão da dialética e da existência. Um dos primeiros conceitos que discute em seu livro Matéria e Memória: ensaio sobre a relação do corpo com o espírito é o de imagem. Para ele, não se pode reduzir a matéria à representação que temos dela, assim como não se pode entender a matéria como aquilo que produz em nós representações.

[...] por "imagem" entendemos uma certa existência que é mais do que aquilo que o idealista chama uma representação, porém menos do que aquilo que o realista chama uma coisa - uma existência situada a meio caminho entre a "coisa" e a "representação" (BERGSON, 1999, p. 2).

Na filosofia contemporânea, o termo representação persiste, mas em alguns casos esta filosofia adota um segundo significado para a imagem quando quer acentuar o caráter ou a origem sensível das ideias ou representações de que o homem dispõe. Bergson já apontava isso em seu pensamento:

\footnotetext{
Iremos fingir por um instante, que não conhecemos nada das teorias da matéria e das teorias do espírito, nada das discussões sobre a realidade ou a idealidade do mundo exterior. Eis-me, portanto em presença de imagens, no sentido mais vago em que se possa tomar essa palavra, imagens percebidas quando abro meus sentidos, não percebidas quando os fecho (BERGSON, 1999, p. 11).
}

A forma como Bergson trata a imagem, nesta fala, vem coincidir com a forma com que muitos teóricos da arte e filósofos contemporâneos vêm se referindo a ela, pois estudos sobre a imagem vêm sendo recorrentes em diversas pesquisas voltadas para as questões dos Estudos Culturais e o mundo contemporâneo tem apresentado formas diversas de relação do homem com as imagens. Dessa forma, percebemos que os estudos, especialmente no âmbito acadêmico da História da Arte que vivenciamos desde a década de 80, deslocam-se para o campo da Cultura Visual.

Um dos importantes autores da recente Teoria Francesa das Artes Plásticas, George Didi-Huberman $(1998 ; 2013)$ avança nesse campo e é expoente nos estudos da imagem. Ele nos impulsiona a olhar para as imagens como sendo ao mesmo tempo paixões e questões, e orienta que façamos delas os "olhos da história" e com elas tomemos posições. Trata com ironia a tese de “[q]ue ver só se pensa e só se experimenta em última instância numa experiência do tocar" (DIDI-HUBERMAN, 1998, p. 31), que é a premissa da fenomenologia da percepção em Merleau-Ponty, como se o ato de ver acabasse sempre pela experimentação tátil. A fenomenologia sempre foi bem recebida no campo da arte, mas Didi-Huberman quebra com ela quando diz que "devemos fechar os olhos para ver quando o ato de ver nos remete, nos abre a um vazio que nos olha, nos concerne e, em certo sentido, nos constitui" (ibid, 1998, p. 31).

Para Rancière (2012), o termo imagem estabelece duas coisas diferentes: a relação simples que produz a semelhança de um original e a alteração da semelhança, que é um 
jogo de operações chamada arte. A alteração pode assumir diversas formas como "a visibilidade conferida a pinceladas inúteis para nos fazer saber o que é representado num retrato" (RANCIÈRE, 2012, p. 15), um alongamento de corpos, uma locução exagerada que atrapalha a compreensão de uma ideia. E é nesse sentido que Rancière aponta:

\begin{abstract}
[...] a arte é feita de imagens, seja ela figurativa ou não, quer reconheçamos ou não a forma de personagens e espetáculos identificáveis. As imagens da arte são operações que produzem uma distância, uma dessemelhança. Palavras descrevem o que o olho poderia ver ou expressam o que jamais verá, esclarecem ou obscurecem propositalmente uma ideia. Formas visíveis propõem uma significação a ser compreendida ou a subtraem. Um movimento de câmera antecipa um espetáculo e descobre outro, um pianista inicia uma frase musical "atrás" de uma tela escura. Todas essas relações definem imagens. Isso quer dizer duas coisas. Em primeiro lugar as imagens da arte, enquanto tais, são dessemelhanças. Em segundo lugar, a imagem não é uma exclusividade do visível. Há um visível que não produz imagem, há imagens que estão todas em palavras (RANCIÈRE, 2012, p. 15-16).
\end{abstract}

E para Emanuele Coccia, a imagem produz efeitos perfeitamente isomórficos, e, dessa forma, suscita a imitação, gera semelhanças. "Se a eficácia da imagem coincide com a sua multiplicação, com a sua reprodução em sujeitos estranhos, ao reproduzir-se a imagem não constitui um novo sujeito, porém é objeto de imitação espontânea" (COCCIA, 2010, p. 74), mas apenas segundo a forma, não segundo a matéria. Ser influenciado significa ter acolhido uma forma que vem do exterior sem ser alterado. Imitação e influência são a vida própria do sensível que para o filósofo é a imagem. Nos apropriamos da imagem e a percebemos por meio das sensações.

São olhares diferentes para a imagem. Multiplicidades que acabam por constituir paradoxos e nos chamam a atenção para o lugar da imagem em nossa constituição de sujeitos no mundo e também para o significado dela no campo da arte e do ensino.

O paradoxo da imagem para Didi-Huberman é operado pela chave do olhar na relação com o outro, manifesto por duas posturas dicotômicas de um sujeito cindido diante da imagem: o homem da crença - aquele que sempre quer ver algo além do que se vê - e o homem da tautologia - que nega ver algo além da imagem, além do que é visto. Estas posturas que o autor cria, representam, a certo modo, as abordagens tradicionais do saber sobre as obras de arte. Esta discussão sobre tautologia e crença é um dos pontos de discussão dessa pesquisa no que se refere às imagens. Como superar essas perspectivas no trabalho com os professores e professoras? Como fazê-los criar além da tautologia e da crença? Essas questões me reportam ao cotidiano da escola e das aulas de Artes, que tratam as imagens a partir dessas duas atitudes - a da crença e a da tautologia. Às vezes a imagem é posta diante do aluno como algo que remete tão somente ao visível, sem produzir nenhum sentido. Outras vezes ela é apresentada numa determinada representação onde sua variabilidade é anulada, eliminando assim as possibilidades de distância e preenchimento entre ela e o observador.

Na sua teoria sobre crença e tautologia, Didi-Huberman (1998) busca encontrar um exemplo para o extremo da atitude do homem da tautologia e então apresenta a MinimalArt. A arte minimalista é aquela dotada, como dizia Ad Reinhardt, de "mínimo conteúdo de arte" (DIDI-HUBERMAN, 1998, p. 49). Uma arte produzida por puros e simples volumes, "volumes sem sintomas e sem latências, portanto objetos tautológicos" (ibid, 
1998, p. 50). A estética deste movimento poderia ser sintetizada nesta expressão: What you see is what you see (O que você vê é o que você vê) (ibid, 1998, p. 55). Dois artistas americanos minimalistas, Donald Judd e Robert Morris tinham como objetivo em suas produções entender o que seria ilusão na arte. Judd afirmava que "tudo o que está sobre uma superfície tem um espaço atrás de si” (ibid, 1998, p. 52). Sua busca era a de produzir um objeto visual despido de ilusionismo; um objeto em três dimensões, produtor de sua própria espacialidade específica, pois para ele a pintura e a escultura inventam espaços além delas mesmas. Os minimalistas apresentados no texto de Didi-Huberman, por meio de seus objetos visuais, rejeitam toda a ilusão, todo o detalhe, toda a temporalidade, todos os jogos de significações, toda a forma de antropomorfismo na busca da especificidade do objeto.

Por mais que os artistas minimalistas tentassem defender a especificidade de seus objetos visuais, a sua própria fala contradiz os preceitos construídos por eles. DidiHuberman desconstrói a teoria do objeto específico que os minimalistas apresentam a partir de um olhar mais atento aos enunciados tautológicos que Donald Judd e Frank Stella trazem. A palavra presença, por exemplo, é dita por Stella em ocasião de uma entrevista com o crítico de arte Bruce Glaser, num contexto onde ela não caberia no universo teórico da arte minimalista. Isto demonstrou fragilidade na teoria e apontou diversos outros adjetivos, referentes ao objeto visual e sua simplicidade, colocando-o no mundo da qualidade. Numa defesa sobre a simplicidade da arte minimalista, Judd diz: "As formas, a unidade, [...] a ordem, a cor são específicas, agressivas e fortes" (ibid, 1998, p. 62); estes adjetivos, para Didi-Huberman são carregados de ressonâncias estranhas, e, especialmente as palavras agressivas e fortes, para ele, "evocam um universo da experiência intersubjetiva, portanto um propósito relacional" (ibid, 1998, p. 62) apresentam uma contradição. "Esse apelo à qualidade de ser, à força, à eficácia de um objeto, constitui, no entanto, uma deriva lógica - na realidade fenomenológica - em relação à reivindicação inicial de especificidade formal” (ibid, 1998, p. 62). Esta consideração, para o autor, demonstra que ao mesmo tempo em que o objeto minimalista foi pensado como "específico, abrupto, forte, incontrolável e desconcertante", ele tornouse frente a seu espectador "uma espécie de sujeito" (ibid, 1998, p. 63). O objeto aqui acaba por tentar ser representado e desta forma desconstrói aquilo que Didi-Huberman considera como imagem.

Robert Morris, também artista minimalista, traz em sua produção uma experiência fenomenológica na qual apresenta três objetos formalmente iguais em posições diferentes na sua relação com o espectador. Nesta experiência "há, portanto, tempos, durações atuando em ou diante desses objetos supostos instantaneamente reconhecíveis. Há relações que envolvem presenças [...]" (ibid, 1998, p. 66). Instala-se aqui o paradoxo dos objetos minimalistas. De um lado, a especificidade da forma e do volume e, de outro, a presença e a relação. No olhar do autor, a experiência de Morris derruba a tentativa dos minimalistas de eliminar o antropomorfismo. E é neste momento que o autor abre espaço para dizer que não dá para escolhermos entre o que vemos e o que nos olha, mas sim nos inquietarmos com o entre. É o momento de pensar as contradições e buscar a dialética que estas proporcionam. Com a experiência de Tony Smith e seu cubo, Didi-Huberman amplia seu olhar sobre o antropomorfismo presente nas esculturas minimalistas e traz para a reflexão a questão da dupla distância. 
É a partir daqui que o autor integra duas redes conceituais benjaminianas: a da aura e a da imagem dialética. Para Benjamin, um primeiro aspecto que confere à aura é o poder da distância. Aquilo que nos permite estar ao mesmo tempo próximo e distante é chamado por ele de experiência dialética, que se apresenta como um paradoxo e que nos coloca diante de um segundo aspecto da aura: o poder do olhar. Para Didi- Huberman, "Sentir a aura de uma coisa é conferir-lhe o poder de levantar os olhos [...] esta é uma das fontes mesmas da poesia" (1998, p. 148). Esse olhar é tratado aqui como aquele que deixa essa visão do objeto se desdobrar como pensamento, de tornar a se converter em tempo. E é ainda nessa experiência que Benjamin reconhece um poder da memória onde "todos os tempos nela serão trançados, feitos e desfeitos, contraditos e superdimensionados" (ibid, 1998, p. 149). O cubo preto de Tony Smith se mostra a quem o olha não somente como um objeto específico, mas dá a compreender que pulsa entre a simples forma e a presença. Pode-se dizer então que é um objeto aurático aquele "cuja aparição desdobra para além de sua própria visibilidade, o que devemos denominar suas imagens em constelações ou em nuvens, que se impõe a nós como outras tantas figuras associadas [...]" (ibid, 1998, p. 149). Constelação e cartografia: vejo aqui uma possibilidade de conexão metodológica relevante para minha pesquisa a partir do entendimento de que uma imagem nunca está só. Dela explode uma constelação. Para Benjamin (1984), a estrutura constelar que ele apresenta em seus escritos pode também ser observada em diferentes contextos, inclusive no contexto das imagens, pois ao invés de pensarmos as imagens como uma progressão linear da história, podemos pensá-las como fragmentos em um grande território de estrelas que se cruzam, apagam e aparecem iluminando diferentes elementos de diferentes épocas. Imagens que se repetem num sempre recomeço considerando-se as várias formas de significação que elas promovem. A esta perspectiva também aliamos o contexto do pensamento

\footnotetext{
Incansável, o pensamento começa sempre de novo, e volta sempre, minuciosamente, às próprias coisas. Esse fôlego infatigável é a mais autêntica forma de ser da contemplação. Pois ao considerar um mesmo objeto nos vários estratos de sua significação, ela recebe ao mesmo tempo um estímulo para o recomeço perpétuo e uma justificação para a intermitência do seu ritmo. Ela não teme, nessas interrupções, perder sua energia, assim como o mosaico, na fragmentação caprichosa de suas partículas, não perde sua majestade. Tanto o mosaico como a contemplação justapõem elementos isolados e heterogêneos, e nada manifesta com mais força o impacto transcendente, quer da imagem sagrada, quer da vontade. $\mathrm{O}$ valor desses fragmentos de pensamento é tanto maior quanto menor sua relação imediata com a concepção básica que lhes corresponde [...] (BENJAMIN, 1984, p. 50-51).
}

Pensar em imagem e constelações implica em pensar a imagem como algo que forma e pode transformar, e nos faz questionar aquilo que somos. O importante é a relação que se tem com a imagem. É o espaço que existe entre a imagem e nós, espaço esse que nos invade, que nos derruba e nos modifica. Como lidar, na pesquisa, com a experiência de construir constelações? São os conceitos de imagem crítica e imagem dialética que me ajudam a refletir e construir caminhos para essa indagação.

O ver, o crer e o olhar são pontos debatidos na teoria da imagem na qual se debruça Didi-Huberman (1998). E é em Benjamin que ele busca elucidação iniciando pelo conceito de culto, onde vai abrindo as dimensões do conceito de aura e dizendo que ela 
deve ser secularizada, dispensada de votos religiosos, dando à aparição o caráter da "imanência visual e fantasmática dos fenômenos e objetos", eliminando assim sua "fictícia região de transcendência" (DIDI-HUBERMAN, 1998, p. 157-158).

Quando fala sobre a imagem crítica, Didi-Huberman se apoia também em Benjamin e em sua teoria da imagem dialética. Tem-se, então, uma relação muito pertinente entre uma dimensão histórico-crítica anacrônica que atravessa a produção e a recepção de imagens e a dialética do ver que se faz corpo e espaço imaginativos. "Falar de imagens dialéticas é no mínimo lançar uma ponte entre a dupla distância dos sentidos (os sentidos sensoriais, o ótico e o tátil, no caso) e a dos sentidos (os sentidos semióticos, com seus equívocos, seus espaçamentos próprios)" (DIDI-HUBERMAN, 1998. p. 169). Nesse processo, a relação dialética permite a leitura do instante presente e o reconhecimento do tempo histórico no qual se vive. E partindo desta questão é que Didi-Huberman discute a presença pensando o conceito de forma na imagem, na obra de arte.

O que é uma forma com presença? Esta é a pergunta que impulsiona DidiHuberman na busca de uma conceituação da forma. Para tanto ele propõe que se produza uma "crise de palavras - uma crise portadora, se possível, de efeitos críticos e construtivos" (ibid, 1998. p. 201). Retoma o cubo de Tony Smith e compara os conceitos de presença advindos das críticas de Michael Fried, que rejeita a presença, e de George Steiner, que reivindica a presença. Didi-Huberman vê nestas duas posições a manutenção do dilema entre a tautologia e a crença. E é no decorrer de suas pesquisas que o autor vai investindo nesta "crise" de palavras e apresenta um conceito de que a forma seria apenas um corolário do fechamento já operado pela palavra presença durante diferentes momentos da história da arte e da filosofia. Mas o objetivo de Didi-Huberman não é de fechar um conceito, e sim de abri-lo, e abrir no sentido de processo e não em termos de coisas fixas recolocando a relação em sua prioridade nos objetos mesmos e devolvendo às palavras, aos conceitos, sua dimensão inicial.

A ideia do autor não é a de formar um conceito técnico, mas sim abrir um campo de reflexão onde a imagem possua uma dimensão cognitiva, histórica e de pensamento, e possa ser tratada como um espaço aberto, multidimensional. Um espaço de tempo acumulado, de rememoração, de impressões revistas, de dialética a uma história revisitada no "agora". Fala de forma quase poética sobre o aspecto fenomenológico do conceito de imagem em seus diferentes matizes, dando valor ao espaço tecido entre o observador e a obra de arte como um lugar no qual se abre o incomensurável que poderá ser completado e interpretado, ou não, pelo olhante. E é nessa possibilidade, nessa discussão, que a recepção e a produção de imagens podem ser pensadas como um campo de tensões dialéticas. Um campo que atravessa a história e sobrevive.

A história da arte existe? A história da arte nasceu? Essas são perguntas feitas por Didi-Huberman (2013) em seu estudo sobre a sobrevivência das imagens. A palavra sobrevivência é discutida, conceituada e reconceituada a partir de Aby Warburg, historiador da arte nascido em Hamburgo, na Alemanha, no ano de 1866 e que apresenta um modelo cultural da história que se exprime por "obsessões, remanências e reaparições das formas" (ibid, 2013, p. 25).

Voltando às duas perguntas do parágrafo anterior, Didi-Huberman arrisca dizer que a história da arte como o discurso histórico que não nasce nunca. Sempre recomeça. E 
constata que "a história da arte, como disciplina, recomeça vez após outra. Toda vez, ao que parece, que seu próprio objeto é vivenciado como morto...e como renascendo" (ibid, 2013, p. 13).

Para o autor existe no continuum cronológico, a partir da História Natural de Plínio, indícios historiográficos gregos. $\mathrm{E}$ em meados do século XVI, Vasari ${ }^{4}$ produz escritos históricos e estéticos apontando a morte da arte antiga, causada pela Idade Média, e resgatada por um importante movimento denominado renascimento, que inicia com Giotto $^{5}$ e chega a seu ápice com Michelângelo ${ }^{6}$, o grande gênio neste processo de ressurreição. "A partir daí - a partir desse renascimento, ele próprio surgido de um luto parece ter podido existir algo a que se chama história da arte" (ibid, 2013, p. 13).

Por volta da metade do século XVIII, em um contexto que já não era do renascimento humanista, mas sim do renascimento neoclássico, Winckelmann - (1475 1564) historiador e arqueólogo alemão - inventa a história da arte no sentido moderno da palavra história. Foi o primeiro a aplicar de forma sistemática categorias de estilo à história.

\begin{abstract}
Winckelmann [...] representaria, no campo da cultura e da beleza, a virada epistemológica de um pensamento sobre a arte para a era - autêntica, já "científica" - da história. A história de que se trata já era "moderna", já era "científica", no sentido de ultrapassar a simples crônica de tipo pliniano ou vasariano [...] Winckelmann teria inventado a história da arte, começando por construir, para além da simples curiosidade dos antiquários, algo como um método histórico. Deste ponto em diante, o historiador da arte já não se contentou em colecionar e admirar seus objetos: como escreveu Quatremère, ele analisou e decompôs, exerceu seu espírito de observação e de crítica, classificou, aproximou e comparou, "voltou da análise para a síntese", a fim de "descobrir as características seguras" que dariam a qualquer analogia sua lei de sucessão. Foi assim que a história da arte se constituiu como um "corpo", como saber metódico e como uma verdadeira "análise dos tempos" (DIDIHUBERMAN, 2013, p. 14-15).
\end{abstract}

Olhando para essa produção de Winckelmann, que é apresentada sob o título História da arte entre os antigos, Didi-Huberman aponta diferentes contradições e questiona essa história da arte inventada e que muitos historiadores e professores replicam em seus estudos e em suas aulas hoje. Para ele, as imagens não são um modelo de transmissão pressuposto pela imitação em que transforma a estética clássica, e nem as simples crônicas representativas - figuras de contextos numa sucessão cronológica e linear - tal como propunha a história positivista da arte. Ao olhar para a história da arte, nos faz repensar os modos de conduzir a sua temporalidade, e a considerar movimentos e ritmos que formam anacronismos nesta história. E é neste sentido que seus estudos se aproximam do pensamento de Aby Warburg, que um século e meio depois de Winckelmann publicou um pequeno texto intitulado Dürer e a Antiguidade italiana e nele analisou a imagem da obra $A$ morte de Orfeu (Figura 1).

\footnotetext{
${ }^{4}$ Giorgio Vasari (1511-1574): pintor e arquiteto italiano conhecido pelos seus escritos de biografias de artistas italianos.

${ }^{5}$ Giotto de Bondone (-1337): intor e arquiteto italiano mais conhecido pela introdução da perspectiva na pintura. É considerado o precursor do renascimento italiano.

${ }^{6}$ Michelângelo (1475-1564): pintor, escultor, poeta e arquiteto italiano. Considerado um dos maiores artistas do ocidente.
} 
Figura 1- A morte de Orfeu - Albrecht Dürer, 1494. Bico de pena sobre papel.

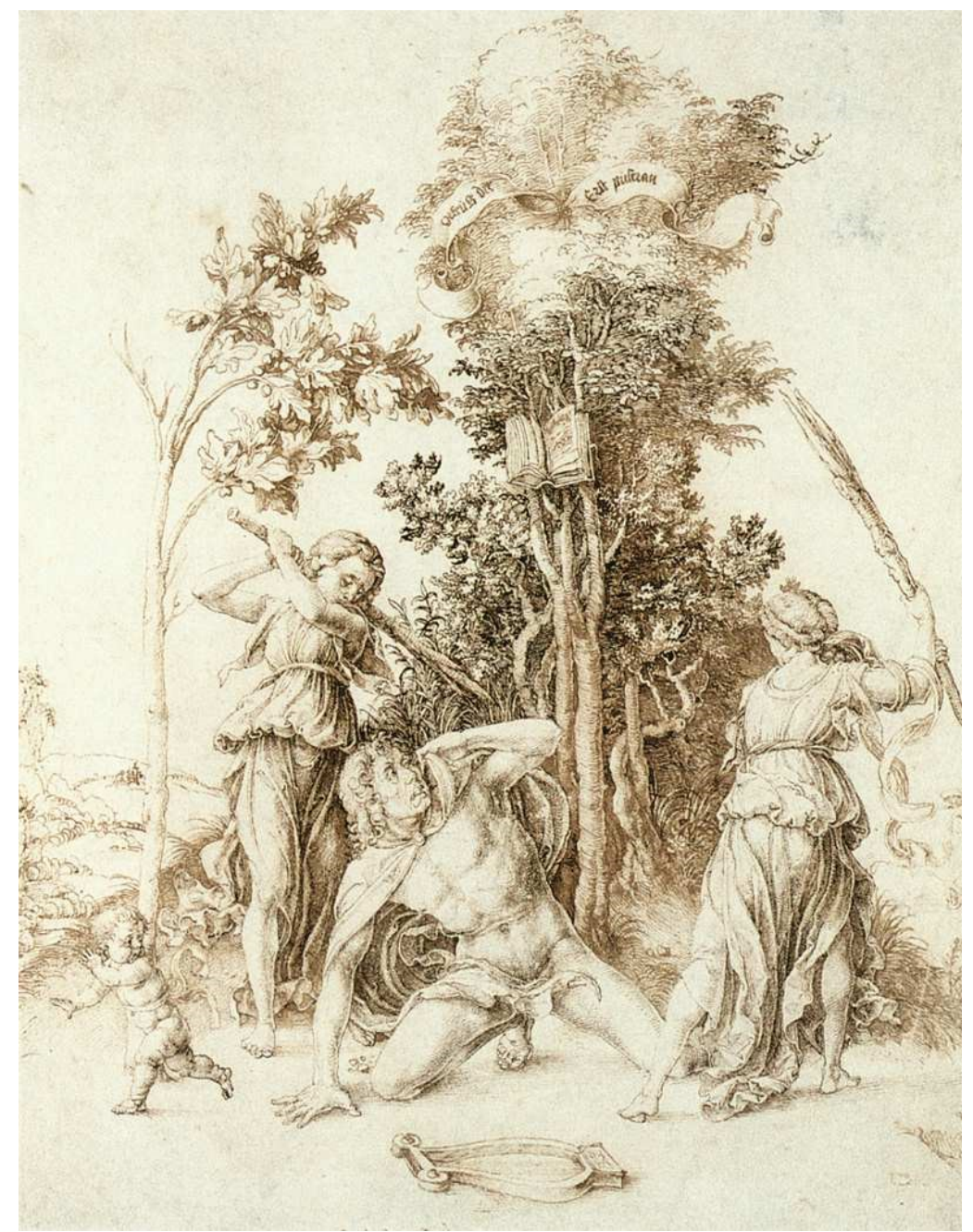

Fonte http://warburg.chaa-unicamp.com.br/obras/view/576

Nessa análise, Warburg decompôs, desconstruiu todos os modelos de conhecimento usados na história da arte de Vasari e de Winckelmann e também desfez o que a história da arte ainda hoje toma como seu início.

\begin{abstract}
Warburg substituiu o modelo natural dos ciclos de "vida e morte", "grandeza e decadência", por um modelo decididamente não natural e simbólico, um modelo cultural da história, no qual os tempos já não eram calcados em estágios biomórficos, mas se exprimiam por estratos, blocos híbridos, rizomas, complexidades específicas, retornos frequentemente inesperados e objetivos sempre frustrados. Warburg substituiu o modelo ideal das "renascenças", das "boas imitações" e das "serenas belezas" antigas por um modelo fantasmal da história, no qual os tempos já não se calcavam na transmissão acadêmica dos saberes, mas se exprimiam por obsessões, "sobrevivências", remanências, reaparições das formas. Ou seja, por não-saberes, irreflexões, por inconscientes do tempo (DIDI-HUBERMAN, 2013, p. 25).
\end{abstract}

Segundo Didi-Huberman, a história da arte, para Warburg, é "o contrário de um começo absoluto, de uma tábula rasa" (DIDI-HUBERMAN, 2013, p. 27). Esta é uma 
forma de olhar para essa disciplina que afronta os elementos estéticos clássicos e que, de certa forma, transtorna as coisas já estabelecidas e bem aceitas pelos "leitores modernos". Warburg, "nosso fantasma: em algum lugar dentro de nós, mas em nós inapreensível, desconhecido" (ibid, 2013, p. 27). Ele tinha aversão à história da arte estetizante e para reagir a esse descontentamento, essa insatisfação, ele se pôs em constante movimento recusando a imobilidade infecunda. Pôs em prática um permanente deslocamento - nos pontos de vista filosóficos estabelecidos, nos campos de saber conformados, nas hierarquias culturais, nos tempos históricos, nos lugares geográficos. Em seu contínuo movimento, quase como um nômade, constrói uma subjetividade desterritorializada, assim como o esquizo apresentado por Deleuze e Guattari (1995). Esses autores dizem existir uma semelhança entre o nômade e o esquizo: "o nômade, como o esquizo, é o desterritorializado por excelência, aquele que foge e faz tudo fugir. E que faz da própria desterritorialização um território subjetivo" (PELBART, 2002, p. 34).

Esse jeito de ser esquizo, de Warburg, se apresenta desde sua juventude. Estudou arqueologia e filosofia clássicas, antropologia, psicologia social, teorias da arte, que para Didi-Huberman foi "mais do que um saber em formação, foi antes um saber em movimento que aos poucos se constituiu, pela ação - aparentemente errática - de todos esses deslocamentos metodológicos” (DIDI-HUBERMAN, 2013, p. 32-33).

Nesse aspecto, vejo Warburg como um historiador da arte rizomático. Aponto aqui um paradoxo: história e rizoma, quase um oximoro, pois enquanto a história, mesmo anacrônica e não linear, considera o presente, o passado e o futuro, ordem que nos leva a pensar em um movimento arborescente, sequencial, o rizoma que Deleuze e Guattari (1995) apresentam parte dos princípios de conexão e heterogeneidade, isso significa que ele pode e deve ser conectado a qualquer outro. É uma postura que nos permite, assim como o estudo de Warburg para a história da arte, desconstruir nosso olhar estruturante.

A biblioteca imaginada por Warburg em 1889 e erguida entre 1900 e 1906 (Kulturwissenschaftliche Bibliothek Warburg) tem características rizomáticas pelo princípio de cartografia, onde rizoma é mapa e não decalque. E, como mapa, constrói o inconsciente e é passível de ser desmontável, reversível, suscetível de receber modificações a todo o momento. E pelo princípio da multiplicidade. Esse princípio mostra que o rizoma é constituído por linhas de segmentaridade que permitem que ele seja estratificado, territorializado, organizado, mas constitui-se também por linhas de desterritorialização pelas quais ele foge sem parar. Dessa forma, se percebe que o rizoma pode ser rompido em um lugar qualquer ao mesmo tempo em que ele pode retomar a outros lugares seguindo outras linhas. O sistema rizomático não compreende o dualismo ou a dicotomia. Faço essas aproximações nas características por ver que a biblioteca de Warburg foi pensada e construída como "espaço do pensamento" onde "a história da arte como disciplina acadêmica foi posta à prova de uma desorientação organizada: em todos os pontos em que havia fronteiras entre disciplinas, a biblioteca procurava estabelecer ligações" (DIDI-HUBERMAN, 2013, p. 35).

$\mathrm{Na}$ incessante busca de uma forma original que desse conta de expor seus deslocamentos, em especial sobre as imagens, a partir de teorias fundamentadas que não fossem esquemáticas ou empobrecedoras e que respeitassem as singularidades, é que Warburg trabalhou até sua morte, em 1929, em um projeto chamado Mnemosyne $e^{7}$ o atlas

\footnotetext{
${ }^{7} \mathrm{Na}$ mitologia grega, a personificação clássica da memória, mãe das nove Musas.
} 
de imagens. Este atlas consistia em uma exposição fotográfica com fotos das imagens de obras existentes na grande coleção reunida por ele em sua biblioteca. As fotografias eram fixas com pequenos prendedores, fáceis de manipular, em telas de tecido preto esticados sobre estrados de madeira que mediam um metro e meio por dois. O conjunto do atlas tornava-se um material imagético extremamente diversificado que abria diferentes possibilidades de construção do conhecimento em história da arte, história da cultura, história das imagens por caminhos rizomáticos e desterritorializados.

Assim, Mnemosyne, segundo Didi-Huberman, é uma espécie de autorretrato estilhaçado do pensamento de Warburg, que se reconhece no relacionamento das imagens entre si, que se perfaz numa nova teoria da função memorativa das imagens. Esta função memorativa é que desenha o conceito warburguiano de sobrevivência. Uma maneira pela qual as imagens retornam, reaparecem, sobrevivem num movimento que constitui o movimento do sintoma que em Warburg se apresenta como a incapacidade de contar a história da arte por meio de uma sequência ordenada de eventos.

[...] entre 1905 e 1911, Warburg havia tentado organizar em quadros regulares - com fileiras, abscissas e ordenadas - esse vocabulário das "formas preestabelecidas" do páthos. Recordamos também o fracasso de uma tentativa dessa natureza intitulada Schemata Pathosformeln. Desde então, Warburg havia compreendido com clareza que não se "esquematiza" a história das imagens, muito menos a história de suas fórmulas patéticas, porque as imagens só se deixam "encaixotar", se me atrevo a dizê-lo, ao serem privadas de sua própria capacidade de metamorfose e sobredeterminação (DIDI-HUBERMAN, 2013, p. 391).

Encaixotar ou encarcerar a imagem é uma forma de não permitir que seus aspectos de reflexo, de ilusão, de duplos possam abrir espaços de criação de vida, multiplicidades de ações que nos possibilitam ver o universo crítico da imagem. Na educação em arte, trabalha-se com diferentes conhecimentos que são mais ou menos especializados, mais ou menos úteis, deixando o campo sempre mais ou menos. Não seria a hora de se pensar em um conhecimento sensível que abrace a experiência como uma forma de aprender e aprender-se? Um conhecimento que venha atravessado de sensibilidade, de incertezas, de singularidades, de corpo? Que seja um acontecimento provocado pela imagem, pelo sensível, pela arte?

Para Didi-Huberman, só conseguimos ver quando assumimos a inelutável cisão do ver. Esta cisão é que abre o vazio e que se configura no meio. Nesse vazio e nesse meio é que o sensível encontra lugar para a percepção. Este lugar, na perspectiva do afeto, é lugar do movimento. Deleuze (1983) apresenta a ideia de afeto a partir de Espinosa, onde afeto - do latim affectio - é uma forma de pensamento vinculada ao nada, a algo não representativo. Deleuze exemplifica isso com o verbo 'querer'. O que queremos sobrecai em alguma coisa, entretanto, o fato isolado de querer não se coloca como ideia, mas sim como afeto. Sendo assim, o afeto implica em uma ideia, contudo, são modos diferentes de pensamento. Ele define, a partir de Espinosa, o afeto como: "a variação contínua da força de existir na medida em que essa variação é determinada pelas idéias que se tem" (DELEUZE, 1983, p. 16). Considerando essa variação como uma sucessão de ideias que se afirmam em nós. O afeto é um outro tipo de informação - não apenas intelectual, nem apenas corporal - que move e instiga a perceber ou a pensar tudo de maneira diferente. Ele funciona como um impulso para o pensamento que, de modo reflexivo, promove um 
novo olhar, um novo ouvir, um novo sentir sobre as coisas do mundo. Um movimento, uma variação do tom emocional presente em toda percepção, mas que não se confunde com nenhum dado dela e nem é algo da ordem do pensamento, mas que o estimula a reconsiderar o que viu e o que pensou.

Reflito sobre estas possibilidades aqui, a despeito de suas limitações e de sua contextualização histórica, a fim de aguçar e explicitar minha crítica a toda e qualquer proposta de encarceramento da imagem. Penso que qualquer teoria que busque sistematizar, criar etapas, tem como base aquilo que as pessoas têm de igual e o que me interessa é justamente a diferença, a singularidade. Quando se tem um modo de olhar a imagem, se está se recriando como vida, e a arte agencia as formas de vida já existentes. A virada visual, a virada em si é isso, é quando a arte promove, mobiliza modos de vida. E esta mobilização é o afeto.

\section{REFERÊNCIAS}

ABBAGNANO, Nicola. Dicionário de filosofia. 5. ed. São Paulo: Martins Fontes, 2007.

BENJAMIN, Walter. Origem do drama barroco alemão. Tradução Sérgio Rouanet. São Paulo: Brasiliense. 1984.

BERGSON, Henri. Matéria e Memória: Ensaio sobre a relação do corpo com o espírito. Tradução Paulo Neves. 2 ed. São Paulo: Editora Martins Fontes, 1999.

COCCIA, Emanuele. A Vida Sensível. Tradução Diego Cervelin. Florianópolis: Cultura e Barbárie, 2010.

DELEUZE, Gilles. Cinema 1: Imagem-Movimento. São Paulo: Brasiliense, 1983.

DELEUZE, Gilles; GUATTARI, Felix. Mil platôs: capitalismo e esquizofrenia 2, vol. 1. Tradução de Ana Lúcia de Oliveira, Aurélio Guerra Neto e Célia Pinto Costa. São Paulo: Editora 34, 1995.

DIDI-HUBERMAN, Georges. O que vemos, o que nos olha. Tradução de Paulo Neves. São Paulo: Ed.34, 1998.

, Georges. A imagem sobrevivente: história da arte e tempo dos fantasmas segundo Aby Warburg. Tradução Vera Ribeiro. Rio de Janeiro: Contraponto, 2013.

PELBART, Peter Pál. Poder sobre a vida, potência da vida. Lugar Comum: Estudos de Mídia, Cultura e Democraci. Rio de Janeiro, n. 17, p.33-43, abr. 2002. Disponível em:

$<$ http://uninomade.net/lugarcomum/17/>. Acesso em: 12 nov 2015.

RANCIÈRE, Jacques. O espectador emancipado. Tradução Ivone C. Benedetti. São Paulo: Editora WMF Martins Fontes, 2012.

Recebido em 05/02/2016. Aprovado em 22/03/2016.

Title: Multiplicities of image: art and affects

Abstract: This text is an excerpt of my doctoral study that had as research problem the following question: is it possible, through the sensitive, promote teacher training and Arts teachers with critical and political potential? Training for new teachers who from experience create ways of living and thus create a new art class? Bring reflections about the image, especially the image in art as an exercise of looking, trying to advance the boundaries of the timeline to achieve the image in its multiplicity. From authors such as Georges DidiHuberman, Jacques Rancière, Emanuelle Coccia, Gilles Deleuze and Felix Guattari this text also aims to reflect on how the art mobilizes the affection, promoting, in a reflexive manner, a new look, a new hearing, a new feeling about the world.

Keywords: Image. Affection. Art.

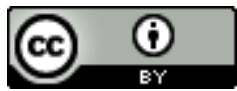

Este texto está licenciado com uma Licença Creative Commons Atribuição 4.0 Internacional. 